\title{
Boyd Body Surface Area Formula
}

National Cancer Institute

\section{Source}

National Cancer Institute. Boyd Body Surface Area Formula. NCI Thesaurus. Code C68650.

The formula to calculate body surface area as described by E Boyd. It is mathematically defined as: BSA $\left(\mathrm{m}^{\wedge} 2\right)=0.0003207 \times\left[\mathrm{Height}(\mathrm{cm})^{\wedge} 0.3\right] \times\left[\right.$ Weight $(\mathrm{g})^{\wedge}(0.7285-(0.0188 \times$ $\operatorname{LOG}(\mathrm{g}))]$ 